\title{
A lean approach to healthcare management using multi criteria decision making
}

\author{
Ramkrishna S. Bharsakade ${ }^{1} \cdot$ Padmanava Acharya $^{1} \cdot$ L. Ganapathy $^{1}$ (D) \\ Manoj K. Tiwari ${ }^{1}$
}

Accepted: 2 November 2020 / Published online: 1 January 2021

(c) Operational Research Society of India 2021

\begin{abstract}
Recent challenges induced by the global pandemic COVID-19 have highlighted the critical importance of coping with a sudden surge in demand for front line healthcare services. Motivated by the success of lean implementation in manufacturing systems, this study attempts to apply the lean principles in healthcare delivery environments. The lean approach begins with the identification of seven types of wastes in any production or service system. This study attempts to identify and prioritize the present in hospitals. The study contributes to the existing body of knowledge in two ways. First, we identify the various sources contributing to the seven basic wastes in healthcare delivery. Second, we prioritize the seven types of wastes and the dimensions contributing to these wastes using a Multi-Criteria Decision Making (MCDM). This paper used the fuzzy analytical hierarchy process approach, which is a well-accepted tool in MCDM. The study was conducted at select hospitals located in and around Pune city in India. We find that waiting, transportation, motion, and defects are dominant in adopting lean practices among the seven wastes. The findings of this study may guide hospital management in strategic planning in adopting a lean healthcare process. To our knowledge, this is one of the first studies to extract, and prioritise lean wastes within the context of the healthcare sector.
\end{abstract}

Keywords Lean wastes $\cdot$ MCDM $\cdot$ Fuzzy AHP $\cdot$ Healthcare $\cdot$ Waste prioritization

L. Ganapathy

ganapathyl@gmail.com

Ramkrishna S. Bharsakade

ramkrishna.bharsakade.2016@ nitie.ac.in

Padmanava Acharya

pacharya@nitie.ac.in

Manoj K. Tiwari

mkt09@nitie.ac.in

1 NITIE, Mumbai, India 


\section{Introduction}

The recent COVID-19 pandemic has exposed the weaknesses associated with global healthcare management. In a few months, the unpredictable and uncontrolled infection spread severely, impacting several sectors worldwide [66]. Several countries' governments were unable to stop or control the spread of COVID19 infection despite several measures. Dela in developing the vaccines worsened the spread day by day, resulting in an unprecedented surge in healthcare demand due to which the entire healthcare supply chain got distressed, testing its resilience $[19,28]$. The pandemic outbreak was a significant source that initiated several political and economic disruptions [58]. In this turbulent environment, healthcare needs to be more resilient.

Many countries are putting earnest research efforts in developing the vaccine for COVID-19 to control the pandemic effectively. Currently, many vaccines are undergoing a phase of human trials with successful results. In the coming times, the COVID-19 vaccine may be available. The substantial degree of fear and anxiety induced by the pandemic may result in a striking outburst in demand for the vaccine requiring the vaccine's mass production in a shorter time. However, it is highly challenging to rapidly distribute a vaccine's mass production in a global setup. This requires a disruptive supply chain resilience with adequate planning, adaptability of the disruptions, and proper coordination. A lean thinking approach can play a crucial role in improving healthcare service quality and operational efficiency in such circumstances.

The lean manufacturing concept became a global phenomenon in the 1990s after the hugely popular book by Womack, describing its lineage to the Japanese automotive manufacturer Toyota [29, 77]. In manufacturing operations, it is well known that a lean system is capable of handling considerable fluctuations in customer demand. Toyota Motor Company had successfully introduced lean tools and techniques in its plants and documented its efforts. Since then, these have been widely accepted and implemented in manufacturing and services [69]. Within the service sector, healthcare is a significant contributor to the economy of several countries. Healthcare delivery systems consist of several processes necessary to maintain or improve humans' physical or mental conditions, compromised due to illness or injury. The processes are termed as curative, aimed to treat the patients, prevent disease, and rehabilitate for post-treatment care [38]. Healthcare services vary significantly in terms of quality and accessibility according to population, income, and location [20]. The increased demand for healthcare services makes it essential to review healthcare processes to improve its performance [5].

Lean philosophy mainly focuses on adding value to the customer by identifying and eliminating various types of waste present in the system [73]. In the healthcare setting, the ultimate customer is the patient seeking healthcare. In contrast, other customers include the patient's relatives, friends, insurance companies, non-government social organizations, among internal customers include doctors, nurses, and employees. Different customers have different expectations, requirements, and perceptions of quality [64]. Lean healthcare begins with 
identifying various sources of wastes and their dimensions; however, healthcare operations are unique in terms of the degree of urgency, degree of complexity, and the customer's role in making it arduous task [48]. The next steps prioritize this waste to eliminate it and achieve a value-added healthcare delivery process. Prioritization of the wastes leads to determine the relative importance of various wastes, which can help filter out the actions to minimize or eliminate these wastes. Lean healthcare implementation can help to develop efficient, competitive, and patient-centric processes [13].

The term leanness is associated with quantifying the overall development and influence of lean initiatives in the organization [61]. In the healthcare context, leanness can be defined as improving overall healthcare system performance in terms of budget and service time. Healthcare systems need to improve their performance in terms of healthcare costs, utilization of healthcare resources, quality of care, the efficiency of diagnostic methods, time to treat an increasing number of patients, and arrangement of healthcare facilities [6]. Leanness can be improved by eliminating lean wastes present in the system. It is useful to prioritize the improvement opportunities and enhance the healthcare systems' leanness to bring about speedy and noticeable performance improvements [4]. Therefore it is needed to have a structured framework including all stakeholders to rank different improvement opportunities. As a well-accepted MCDM tool, the fuzzy AHP approach presented in this paper can be useful in developing such a framework. The primary objectives of this study are:

1. To recognize various dimensions of seven basic types of waste in the healthcare processes.

2. To prioritize the identified wastes and their dimensions.

3. To develop a framework of leanness assessment and validate for the healthcare system.

This paper is organized as follows: Sect. 2 discusses lean implementation in healthcare. In Sect. 3, we discuss various wastes and their dimensions present in the healthcare process. Section 4 discusses a fuzzy AHP methodology to prioritize lean wastes. Section 5 presents the results and discussion, and Sect. 6 presents the conclusions.

\section{Lean implementation in healthcare}

The earliest efforts to adopt lean thinking in healthcare were made in the UK in 2001 and the USA in 2002 [50]. Over the last two decades, lean implementation in healthcare has rapidly increased, particularly in developing countries [13]. Implementation of Lean in healthcare results in reported tangible benefits like reduction in procedural errors, waiting time, and cost, as well as intangible benefits like increased patient satisfaction, improved healthcare delivery quality, and increased patient motivation $[17,49,62]$. Lean helps to improve efficiency and the effectiveness of the 
healthcare delivery process [50]. Lean implementation in a healthcare organization can be achieved through continuous improvement, which will help healthcare organizations to improve their quality [21]. Lean implementation in healthcare allows health organizations to improve their flow efficiency, cost reduction, and quality [14, 30, 31].

The first step to achieving lean implementation is identifying and eliminating waste to add value to the customers or patients using several lean tools and techniques [73]. Several success stories of lean healthcare applications are available in the literature [13]. Patient cure or pain relief is the utmost goal of the healthcare system [75]. All the healthcare processes are directed to achieve this final goal. Healthcare resources like drugs, pharmaceuticals, medical devices, etc. were used to accomplish this ultimate goal. Healthcare delivery time and the patients' comfort are the critical performance measures of lean implementation in the healthcare system [2]. A multi-skilled workforce is needed in healthcare settings to handle various healthcare processes with the patient's active involvement in the process. The quality improvement in healthcare mostly depends on the frontline staff, which needs to change [46]. and need to increase work satisfaction by providing immediate feedback on efforts. The lean implementation focuses on improving operational effectiveness through reduction of steps in the process [30,31, 41, 70], reduction in staff walking distance [12], reduced time to resolve error alerts, etc.

\section{Waste in lean healthcare}

The seven wastes that are identified by Taichi Ohno for the manufacturing domain are transportation, inventory, motion, waiting, over-processing, overproduction, and defect. In healthcare, the patient's care problems and exasperations are termed as waste [18]. NHS III initially described the significant waste in line with manufacturing waste present in healthcare in 2007, adopted for further study by several researchers [50, 52].

Almost every healthcare process consists of wastes like wasteful motions, procedural errors, communication errors, etc. It is critical to identify the presence of these wastes in day to day healthcare delivery [33]. The presence of waste creates inconsistency in care, unreliable delivery, and interruptions in the healthcare delivery system, which results in high cost, errors, and lack of motivation in the workers $[30,31]$. Any waste, by definition, is a non-value adding activity, the customer identifies value as per their desired performance from the product or the service $[29,77]$. In this study, we have identified various types of waste for the healthcare process as follows.

\subsection{Waste of transportation}

In manufacturing transportation, waste refers to the unnecessary or excessive movement of the product's delivery process. In several situations, a certain amount of transport is essential to add value to the product or the service. In hospital setup, 
several patient movements occur from arrival in the hospital to discharge from the hospital (Eg. movement from department to department, a movement for the lab test, medication, etc.). In many hospitals, the specific equipment types are located at designated places, resulting in unnecessary patient movements. In the healthcare system, unnecessary movements of patients, test samples, medication, and supplies represent the transportation type of waste [22, 24, 37]. Hospital layout can play a vital role in reducing these unnecessary movements as many hospital layouts follow the process type of layout approach.

\subsection{Waste of inventory}

Any supply in excess than required or unavailable when needed is termed inventory waste. Several material supplies, consumables, equipment, and medicine are necessary to perform intended work in a hospital. When these materials are kept in excess, lead to more inventory, high inventories often lead to cash tied up, some stock may expire, including the supplies and medicines [18]. Holding patients for a more extended period than required making the facility unavailable for a further patient can also be termed as an inventory type of waste in the healthcare process [68]. Healthcare inventory management is vital in managing system quality and measuring the delivery process's performance. [32, 67].

As a lean initiative, keeping low inventory levels impaired many manufacturing organizations [18]. Lean philosophy mainly focuses on the patient's needs by continuing the most economical inventory levels. Hospitals need to think of holding a proper inventory of emergency medicines. Maintaining too much inventory may utilize excess funds, but running out of stock may lead to high expenditure for unnecessary movements, ineffective operational procedures, or even harm to the patient [57]. Improved inventory management can help hospitals to reduce other types of wastes also.

One of the forms of inventory waste can be in terms of an excessive storage of patient information. In the present era of information technology, extra information waste may lead to several consequences like efficiency lost, delays in treatment, or complexity in healthcare. Whereas insufficient information leads to complexity in the healthcare process, excessive information waste requires more effort to capture, store, search, and manage it. Relevant details of data need to be achieved with investigations in the proper time, to be retrieved when required.

\subsection{Waste of motion}

While transportation waste focuses on the patients' unnecessary movements (analogical to products), waste of motion refers to unnecessary movements of the employees (analogical to workers) in the healthcare system [37]. It is necessary to make the healthcare process smooth to avoid motion waste [25]. Walking of employees in the hospital to treat the patients can be seen as the most common example of motion waste. Although technicians, nurses, and physicians cannot be stationary in a hospital, one must focus on eliminating unnecessary movements. Movements 
of employees often occur due to improper layout of the hospital. The locations for various employees are mostly stationary, so to provide services to the patient, they have to move from their designated areas to the patient locations. Unavailability of equipment needed at the required place may result in the excess movement of employees. Motion waste can also lead to a delay in providing service to the patient. An improved layout can help to reduce motion waste. Since unnecessary movement does not add any value, it is essential to eliminate motion waste in any healthcare setup.

\subsection{Waste of waiting}

Waiting is simply defined as time lapsed by the patient without any activity. Patients wait in the process due to a delay for the next action to happen. In some cases, employees need to wait in the process due to an unbalanced workload. In the healthcare system, patients typically wait for a doctor's diagnosis, admission to hospital or in-patient ward, or even wait for discharge from the hospital [27]. In many healthcare activities, patient queues are formed due to improper scheduling. Waiting for the pathological or radiological test is very common in hospitals as most of the diagnosis depends on these tests. Long setup time required for some of the healthcare activities also leads to waiting. Waiting by the patients at the healthcare facility for medical examinations leads to low utilization of the available resources leading to an inefficient process [11].

\subsection{Waste of overproduction}

In a manufacturing system, overproduction refers to producing more products than is required by the next process, producing earlier than is needed for the following process, or producing faster than expected [77]. In a healthcare context, it is quite tough to spot overproduction may occur by requesting unnecessary procedures that are not adding value, or ordering more medicines than required, just in case [24, 48]. Studies indicate that in many cases, unnecessary pathological tests or radiological tests were suggested for investigations [50]. In many cases, unnecessary scheduled follow-up was recommended, which can be termed as overproduction waste. In some cases, some unwanted treatments were suggested, which leads to excess efforts by patients as well as employees. Overproduction leads to hiding other wastes, as in the case of a pharmacist requiring more time to process the returned medicines. Increased frequency of tests can also increase patient transportation within the hospital and increase employee movements in the process.

\subsection{Waste of overprocessing}

The over-processing form of waste refers to the misuse of processing itself. Overprocessing mainly occurs when doctors want to do something at a higher level of quality than required by the patient. One example is in terms of requiring duplication of pathological tests [7]. In many cases, more than one blood test is suggested than 
needed. One of the forms of over-processing is about patient information. It may occur in the way of taking unnecessary patient history every time. In some cases, healthcare professionals may repeat the same procedures to show they are taking more care of the patient, which may not always be required. Often, over-processing may result from miscommunication within the staff.

\subsection{Waste of defects}

Defects referred to any activity that was not done as per the required standard. In healthcare, defects or errors are more severe as it can lead to the injury or even death of the patients. Defects in healthcare are usually caused due to procedural mistakes, miscommunications, or wrong diagnoses. In surgical operation, miscommunication may lead to wrong-side surgery, or negligence may occur as some foreign material may remain inside the patient body. Healthcare equipment needs to be appropriately calibrated; otherwise, it may provide wrong results, resulting in the wrong diagnosis.

However, a defect does not always cause harm, and procedural irregularities may lead to rework [18]. In some cases, the wrong diagnosis may lead to re-admission. Several errors occur in healthcare due to incorrect procedures, which may delay the patients' curing. Defect leads to wastage of time as well as resources, which also leads to patient dissatisfaction.

Based on the above discussion, the different types of waste identified in healthcare dimensions are summarized in (Table 1).

\section{Overview of analytical hierarchy process and fuzzy analytical hierarchy process}

Analytical Hierarchy Process (AHP) is one of the most popular techniques used to solve complex multi-criteria decision-making problems to provide an efficient solution involving several criteria for making the decision [60]. Saaty initially proposed AHP $[55,56]$. AHP considers a hierarchical system of objectives, attributes, and alternatives to solve decision-making problems. AHP is based on pairwise comparisons among the various attributes based on the expert's judgment to prioritize these attributes. In this process, the pairwise comparison is based on an understanding representing one factor's dominance over the other. AHP is suitable to handle several decision situations, including idiosyncratic judgments by multiple decisionmakers. AHP also measures consistency in decision making (R. K. [63, 71]. In this process, experts' opinions are used to decompose a problem into a hierarchy [16, 65]. AHP is a beneficial technique to evaluate the influence of the criteria on the objective or the goal of the system under consideration [26].

In the present study, the goal is to identify and prioritize the healthcare system's waste to evaluate its leanness. The approach in the present study is to provide a more responsive and patient-centric healthcare delivery process. While Analytical Hierarchy Process (AHP) method has been extensively used to solve decision-making problems, the conventional AHP method is not precise and is 


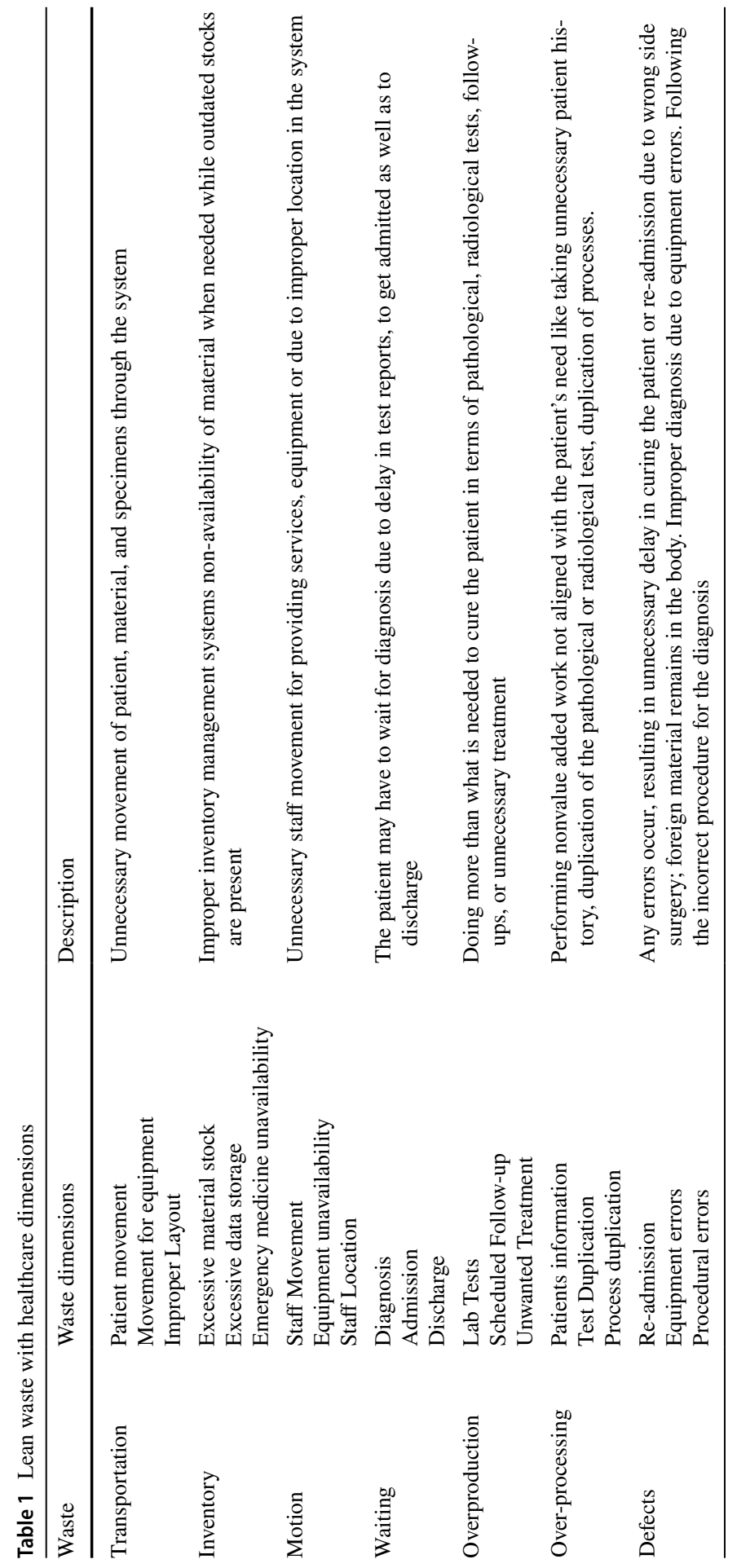


not capable of handling the uncertainty and vagueness involved in linguistic judgments [9, 40, 51]. The fuzzy AHP approach is based on expressing an expert's subjective judgments using fuzzy triangular numbers [10]. Fuzzy AHP can transform qualitative judgments with vagueness into quantitative data using a systematic decision-making approach [34, 54, 74].

The fuzzy AHP methodology is widely acceptable by the researchers, particularly in the prioritization issues. In recent times, [36] use this methodology to prioritize the Halal food supply chain's risk elements. In this study, the authors identified the risk elements associated with Halal supply chains using systematic literature methodology. Authors then use expert professionals to consolidate risk elements and prioritize them using the fuzzy AHP approach. Furthermore, they emphasized a holistic approach that will help to integrate internal processes and outsourcing activities to overcome the risk associated with Halal food SC. [74] identified Indian pharmaceutical supply chain (PSC) barriers by reviewing the literature and expert's opinions. In this paper, the authors used a fuzzy AHP approach to overcome the expert's decision-making process's uncertainty. In this study, the authors scanned 26 barriers in six significant criteria and found that market-related barriers are significant in Indian PSC. This study can help the drug industry by mitigating the obstacles to sustainability and improved quality manufacturing. [3] uses a fuzzy AHP approach for the measurement of property level flood resilience. In this work, the significant flood resilient attributes and their sub-attributes were identified by reviewing the literature. The authors then use FAHP methodology to develop a new model 'Composite Flood Resilient Index' based on the weightage associated with attributes and the sub-attributes. This study developed a quantitative measurement approach for clear and unambiguous flood resilience measurement using an evidence-based method in individual property. [23] discussed the technique for 'Product Service System (PSSs)' by analyzing customer needs for value offerings enhancement. The authors initially developed the 'Quality Function Deployment' model for PSSs using the Kano model to screen customers' requirements and transform into 'Receiver State Parameters (RSPs).' Further, the fuzzy AHP methodology is used to assess these parameters and their intrinsic uncertainty. Finally, they have validated the proposed procedure by implementing it in medical device sector in product oriented regulated market.

The wastes present in the healthcare delivery process are often intangible. Most of the healthcare wastes lead to uncertain perceptions among the patients. The customer involved in the health care process may be different at different stages, like a patient's family waiting outside the operation theatre, wanting to know only about the patient situation. These different customers might define a waste differently, leading to ambiguity and diversity in the meaning of waste. The description of the value of the healthcare process is almost always linguistic and vague. The assessment of the attribute associated with waste present in the system is still subjective and imprecise. This leads to making healthcare management more complex, multifaceted with the involvement of several stakeholders [42]. Therefore, conventional AHP is not adequate to prioritize the waste explicitly. 
The ambiguity associated with human thought can be tackled using the fuzzy set theory, initially proposed by Zadeh [78]. Fuzzy set theory can effectively deal with imprecise linguistics terms used in human subjective judgment and effectively deal with conflicting criteria [9, 43]. The fuzzy AHP approach uses fuzzy sets for pairwise comparison, which may be more suitable to model the vagueness in human preference [47]; Kwong and Bai [40].

The fuzzy AHP approach typically uses the triangular number technique to represent the vagueness associates with linguistic terms [45]. The fuzzy set theory uses a fuzzy membership function that assigns membership grade to each object in the range between 0 and 1 . In literature, one finds several ways of constructing the fuzzy membership functions. In the present study, we have used a triangular membership function as it is widely acceptable and easy to apply [59]. This set used general terms like large, medium, and small to capture the numerical value. A triangular fuzzy number can be expressed as $\tilde{T}=(l, m, u)$ where $l$ is a lower limit, $u$ is an upper limit of the $\tilde{T}$ support, and $m$ is the mid-value [15, 43]. The membership function is defined as shown in Eq. (1).

$$
u_{\tilde{T}}(\mathcal{H})=\left\{\begin{array}{lc}
\frac{x-1}{m-1}, & 1 \leq x \leq m \\
\frac{u-x}{u-m}, & m \leq x \leq u \\
0, & \text { otherwise }
\end{array}\right.
$$

\subsection{Computations for fuzzy AHP process}

The fuzzy AHP approach uses the following steps in the computational procedure for calculating the priority of various waste present in the healthcare delivery process.

Step 1 Development of problem hierarchy

Step 2 Construction of Fuzzy comparison matrix

Step 3 Determining the weights for the criteria involved

Step 4 Calculation of consistency of the judgments

Step 5 Development of final priority framework

\subsubsection{Development of problem hierarchy}

This step aims to identify and prioritize healthcare wastes to assess the healthcare delivery process's leanness, as shown in (Fig. 1). The highest level of this hierarchy in fuzzy AHP represents the goal. The goal of the present study is to assess leanness in the healthcare delivery system kept at Level 1 . The seven wastes present in the healthcare system are considered the criteria representing a level 2 in the hierarchy. Each waste is then subdivided as per its dimensions representing sub-criteria at Level 3. 


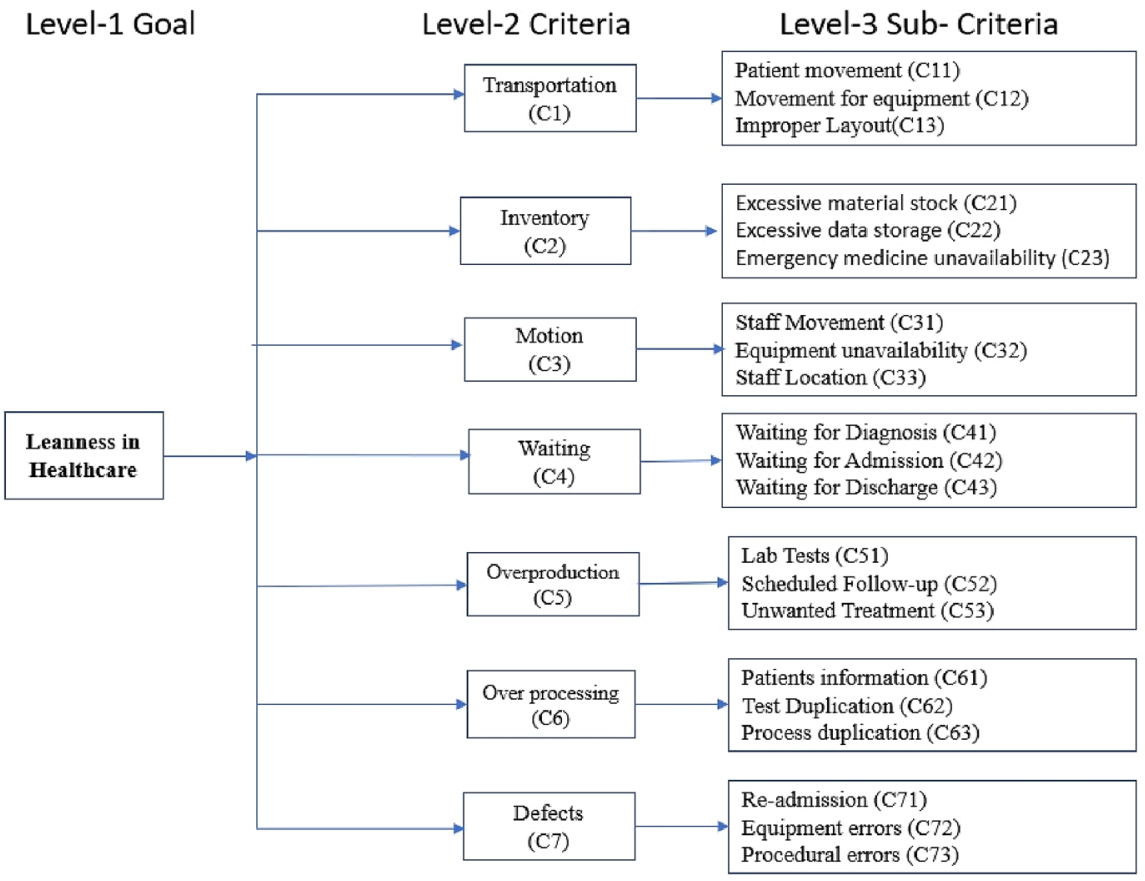

Fig. 1 Hierarchy for fuzzy AHP

\subsubsection{Construction of fuzzy comparison matrix}

A questionnaire was designed to develop a pairwise comparison matrix. The questionnaire is in the form of a conventional AHP approach consisting of a nine-point rating suggested by $[55,56]$. The experts were asked to rank the relative importance of each criterion as well as sub-criteria. After collecting the data, crisp numbers are transformed into fuzzy numbers [44]. The linguistic terms associated with the respective fuzzy number are as shown in (Table 2).

The fuzzy pairwise comparison matrix is as shown in (Table 3).

\subsubsection{Determination the weights for the criteria involved}

In this study, we have used a geometric mean method to compute each criterion's weight, as suggested by $[53,72]$. We calculate the fuzzy geometric mean ( $g i)$ for all the criteria using formula $g i=\left(\prod_{j=1}^{n} \text { Aij }\right)^{1 / n}$ and the fuzzy weights $\left(w_{i}\right)$ for each criterion and sub-criterion using equation were calculated $w_{i=\frac{g i}{\sum_{i=1}^{n} g i}}$. Where $g_{i}$ represents the geometric mean for $\mathrm{i}^{\text {th }}$ criterion., Aij is the pairwise comparison value of criterion $\mathrm{i}$ to criterion $\mathrm{j}$. wi is the weight for ith criterion. The fuzzy weights are then defuzzified to get the normalized weights. Several methods are available for 
Table 2 Linguistic terms used for pairwise comparison

\begin{tabular}{llll}
\hline Crisp scale & Linguistic variables & $\begin{array}{l}\text { Triangular fuzzy } \\
\text { scale }\end{array}$ & $\begin{array}{l}\text { Triangular } \\
\text { fuzzy reciprocal } \\
\text { scale }\end{array}$ \\
\hline 9 & Extremely strong important & $(8,9,9)$ & $(1 / 9,1 / 9,1 / 8)$ \\
8 & Intermediate & $(7,8,9)$ & $(1 / 9,1 / 8,1 / 7)$ \\
7 & Very strong important & $(6,7,8)$ & $(1 / 8,1 / 7,1 / 6)$ \\
6 & Intermediate & $(5,6,7)$ & $(1 / 7,1 / 6,1 / 5)$ \\
5 & Strong important & $(4,5,6)$ & $(1 / 6,1 / 5,1 / 4)$ \\
4 & Intermediate & $(3,4,5)$ & $(1 / 4,1 / 4,1 / 3,1 / 2)$ \\
3 & Moderately important & $(2,3,4)$ & $(1 / 3,1 / 2,1 / 1)$ \\
2 & Intermediate & $(1,2,3)$ & $(1 / 1,1 / 1,1 / 1)$ \\
1 & Equally important & $(1,1,1)$ & \\
\hline
\end{tabular}

Table 3 Fuzzy pairwise comparison matrix for the main criteria

\begin{tabular}{llllllll}
\hline & C1 & C2 & C3 & C4 & C5 & C6 & C7 \\
\hline C1 & $(1,1,1)$ & $(2,3,4)$ & $(1,2,3)$ & $(1 / 4,1 / 3,1 / 2)$ & $(3,4,5)$ & $(2,3,4)$ & $(2,3,4)$ \\
C2 & $(1 / 4,1 / 3,1 / 2)$ & $(1,1,1)$ & $(1 / 4,1 / 3,1 / 2)$ & $(1 / 5,1 / 4,1 / 3)$ & $(1,2,3)$ & $(1 / 3,1 / 2,1 / 1)$ & $(1 / 4,1 / 3,1 / 2)$ \\
C3 & $(1 / 3,1 / 2,1 / 1)$ & $(2,3,4)$ & $(1,1,1)$ & $(1 / 4,1 / 3,1 / 2)$ & $(2,3,4)$ & $(2,3,4)$ & $(1,2,3)$ \\
C4 & $(2,3,4)$ & $(3,4,5)$ & $(2,3,4)$ & $(1,1,1)$ & $(4,5,6)$ & $(3,4,5)$ & $(2,3,4)$ \\
C5 & $(1 / 5,1 / 4,1 / 3)$ & $(1 / 3,1 / 2,1 / 1)$ & $(1 / 4,1 / 3,1 / 2)$ & $(1 / 6,1 / 5,1 / 4)$ & $(1,1,1)$ & $(1 / 3,1 / 2,1 / 1)$ & $(1 / 4,1 / 3,1 / 2)$ \\
C6 & $(1 / 4,1 / 3,1 / 2)$ & $(1,2,3)$ & $(1 / 4,1 / 3,1 / 2)$ & $(1 / 5,1 / 4,1 / 3)$ & $(1,2,3)$ & $(1,1,1)$ & $(1 / 3,1 / 2,1 / 1)$ \\
C7 & $(1 / 4,1 / 3,1 / 2)$ & $(2,3,4)$ & $(1 / 3,1 / 2,1 / 1)$ & $(1 / 4,1 / 3,1 / 2)$ & $(2,3,4)$ & $(1,2,3)$ & $(1,1,1)$ \\
\hline
\end{tabular}

defuzzification. In the present study, we have used the center of area method for defuzzification of the fuzzy weights due to its easiness and efficiency [47]. The nonfuzzy crisp weight $\left(\mathrm{W}_{\mathrm{i}}\right)$ can be calculated by taking the average of $l_{w i}, m_{w i}$ and $u_{w \mathrm{i}}$ [8]. Further, $W_{i}$ represents the non-fuzzy number; it needs to be normalized to get normalized weight $(\mathrm{Ni})$ by dividing each weight by the sum of total non-fuzzy weights [64]. The fuzzy and the normalized weights for each main criterion are shown in (Tables 4, 5, 6, 7, 8, 9, 10 and 11).

\subsubsection{Calculation of Consistency of the Judgments}

Once the pairwise comparison is complete, it is essential to check the consistency of these comparisons. The consistency of fuzzy judgment matrices is tested by defuzzification of the fuzzy pairwise comparison matrix number of consistency models are available in the literature [76]. In the present study, we used a graded mean integration approach to construct a de-fuzzified matrix. Defuzzification of each TFN of the matrix is carried out using the Eq. (6) [39]. 
Table 4 Weights calculations for the main criteria concerning the overall goal

\begin{tabular}{lllllll}
\hline Criteria & \multicolumn{3}{l}{ Fuzzy weight } & & \multicolumn{3}{l}{$\begin{array}{l}\text { Non-fuzzy } \\
\text { weights }\end{array}$} \\
\cline { 2 - 3 } & $\mathrm{L}$ & $\mathrm{m}$ & $\mathrm{u}$ & & $\mathrm{Wi}$ & $\mathrm{NI}$ \\
\hline Transportation (C1) & 0.1104 & 0.2100 & 0.3711 & & 0.2305 & 0.2037 \\
Inventory (C2) & 0.0320 & 0.0584 & 0.1179 & & 0.0694 & 0.0614 \\
Motion (C3) & 0.0806 & 0.1561 & 0.3045 & & 0.1804 & 0.1594 \\
Waiting (C4) & 0.1919 & 0.3415 & 0.5878 & & 0.3737 & 0.3302 \\
Overproduction (C5) & 0.0248 & 0.0445 & 0.0967 & & 0.0553 & 0.0489 \\
Over processing (C6) & 0.0391 & 0.0755 & 0.1522 & & 0.0889 & 0.0786 \\
Defects (C7) & 0.0599 & 0.1140 & 0.2262 & & 0.1334 & 0.1179 \\
\hline
\end{tabular}

$$
D f i=((l i+6 m i+u i) / 6)
$$

The consistency index (CI) for the de-fuzzified matrix of all criteria, as well as the sub-criterion, is calculated using Eq. (7) developed by Saaty $\left(C I=\frac{\lambda \max -n}{n-1}\right)[55,56]$. Where $\lambda \max$ is the highest eigenvalue of the pairwise comparison matrix, and $\mathrm{n}$ represents the pairwise comparison matrix's order.

The consistency ratio is then calculated using the formula $\mathrm{CR}=\mathrm{CI} / \mathrm{RI}$, Where $\mathrm{RI}$ represents the random index. The average RI values are generated for the matrix of order ten and a sample size of 500 by Saaty, as shown in (Table 12). If the CR is less than 0.10 , then it is believed that the derived judgments are consistent, and the weights assigned to the criteria are considered to be reliable.

The defuzzification of the fuzzy pairwise comparison matrix for the main criterion and sub-criterion is shown below (Table 13).

To calculate the Consistency index and consistency ration, we use the following method

(1) Calculate the relative normalized de-fuzzified weight (wj) of each criterion

a. by calculating the geometric mean of the i-th row, and

b. normalizing the geometric means of rows in the comparison matrix.

(2) Calculate matrices A3 and A4 such that A3=A1*A2 and A4=A3/A2, where $\mathrm{A} 2=[\mathrm{w} 1, \mathrm{w} 2, \ldots . ., \mathrm{wj}]^{\mathrm{T}}$. A3 and A4 matrix are shown below,

$$
A 3=\left[\begin{array}{c}
1.57729 \\
0.44586 \\
1.16609 \\
2.554 \\
0.33719 \\
0.56371 \\
0.86048
\end{array}\right] A 4=\left[\begin{array}{c}
7.57019 \\
7.48588 \\
7.42103 \\
7.57762 \\
7.3328 \\
7.36333 \\
7.45869
\end{array}\right]
$$




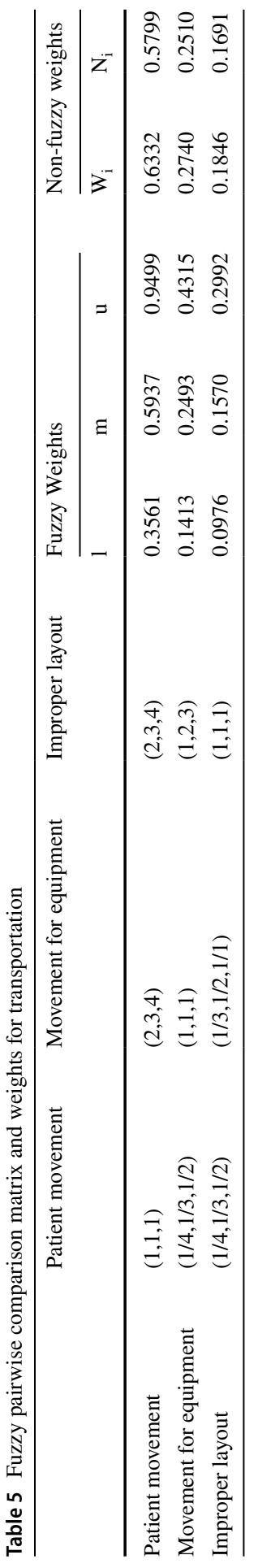




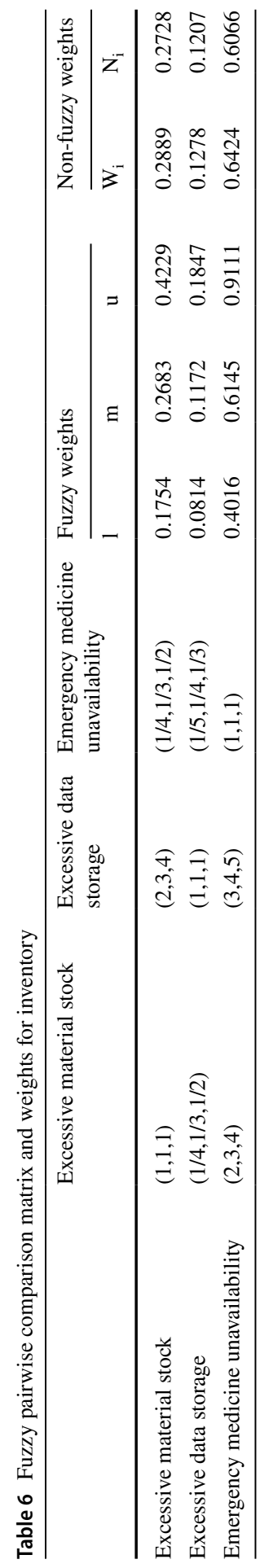




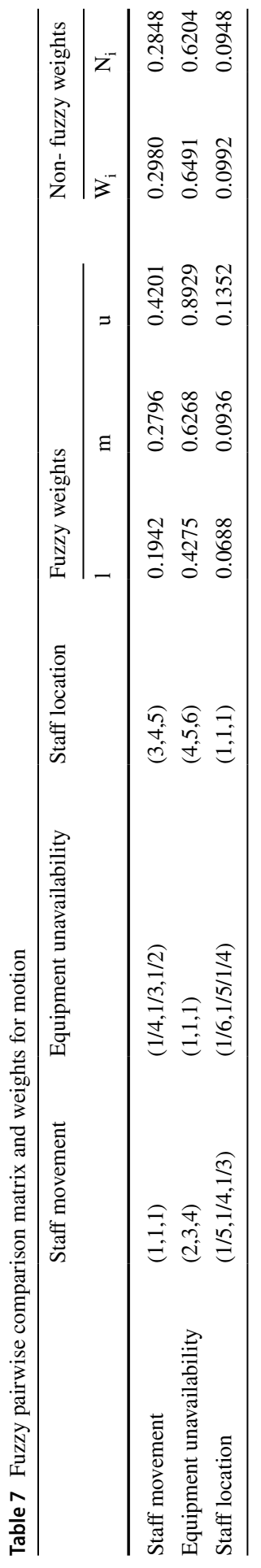


Table 8 Fuzzy pairwise comparison matrix and weights for waiting

Diagnosis Admission Discharge Fuzzy weights Non-fuzzy
weights

\begin{tabular}{|c|c|c|c|c|c|c|c|c|}
\hline & & & & & \\
\hline & & & & 1 & $\mathrm{~m}$ & $\mathrm{u}$ & $\mathrm{W}_{\mathrm{i}}$ & $\mathrm{N}_{\mathrm{i}}$ \\
\hline Diagnosis & $(1,1,1)$ & $(2,3,4)$ & $(3,4,5)$ & 0.4016 & 0.6144 & 0.9111 & 0.6424 & 0.6066 \\
\hline Admission & $(1 / 4,1 / 3,1 / 2)$ & $(1,1,1)$ & $(2,3,4)$ & 0.1754 & 0.2684 & 0.4229 & 0.2889 & 0.2728 \\
\hline Discharge & $(1 / 5,1 / 4,1 / 3)$ & $(1 / 4,1 / 3,1 / 2)$ & $(1,1,1)$ & 0.0814 & 0.1172 & 0.1847 & 0.1278 & 0.1207 \\
\hline
\end{tabular}

Table 9 Fuzzy pairwise comparison matrix and weights for overproduction

\begin{tabular}{|c|c|c|c|c|c|c|c|c|}
\hline & \multirow[t]{2}{*}{ Lab tests } & \multirow[t]{2}{*}{$\begin{array}{l}\text { Scheduled } \\
\text { follow-up }\end{array}$} & \multirow[t]{2}{*}{$\begin{array}{l}\text { Unwanted } \\
\text { treatment }\end{array}$} & \multicolumn{3}{|c|}{ Fuzzy weights } & \multicolumn{2}{|c|}{$\begin{array}{l}\text { Non-fuzzy } \\
\text { weights }\end{array}$} \\
\hline & & & & 1 & $\mathrm{~m}$ & $\mathrm{u}$ & $\mathrm{W}_{\mathrm{i}}$ & $\mathrm{N}_{\mathrm{i}}$ \\
\hline Lab tests & $(1,1,1)$ & $(2,3,4)$ & $(2,3,4)$ & 0.3561 & 0.5937 & 0.9499 & 0.6332 & 0.5799 \\
\hline $\begin{array}{l}\text { Scheduled } \\
\text { follow-up }\end{array}$ & $(1 / 4,1 / 3,1 / 2)$ & $(1,1,1)$ & $(1,2,3)$ & 0.1413 & 0.2493 & 0.4315 & 0.2740 & 0.2510 \\
\hline $\begin{array}{l}\text { Unwanted treat- } \\
\text { ment }\end{array}$ & $(1 / 4,1 / 3,1 / 2)$ & $(1 / 3,1 / 2,1 / 1)$ & $(1,1,1)$ & 0.0976 & 0.1570 & 0.2992 & 0.1846 & 0.1691 \\
\hline
\end{tabular}

Table 10 Fuzzy pairwise comparison matrix and weights for over-processing

\begin{tabular}{|c|c|c|c|c|c|c|c|c|}
\hline & \multirow{2}{*}{$\begin{array}{l}\text { Patients } \\
\text { informa- } \\
\text { tion }\end{array}$} & \multirow[t]{2}{*}{$\begin{array}{l}\text { Test duplica- } \\
\text { tion }\end{array}$} & \multirow[t]{2}{*}{$\begin{array}{l}\text { Process dupli- } \\
\text { cation }\end{array}$} & \multicolumn{3}{|c|}{ Fuzzy weights } & \multicolumn{2}{|c|}{$\begin{array}{l}\text { Non-fuzzy } \\
\text { weights }\end{array}$} \\
\hline & & & & 1 & $\mathrm{~m}$ & $\mathrm{u}$ & $\mathrm{W}_{\mathrm{i}}$ & $\mathrm{N}_{\mathrm{i}}$ \\
\hline $\begin{array}{l}\text { Patients infor- } \\
\text { mation }\end{array}$ & $(1,1,1)$ & $(1 / 6,1 / 5,1 / 4)$ & $(1 / 5,1 / 4,1 / 3)$ & 0.0688 & 0.0936 & 0.1352 & 0.0992 & 0.0948 \\
\hline $\begin{array}{l}\text { Test duplica- } \\
\text { tion }\end{array}$ & $(4,5,6)$ & $(1,1,1)$ & $(2,3,4)$ & 0.4275 & 0.6267 & 0.8929 & 0.6490 & 0.6203 \\
\hline $\begin{array}{l}\text { Process dupli- } \\
\text { cation }\end{array}$ & $(3,4,5)$ & $(1 / 4,1 / 3,1 / 2)$ & $(1,1,1)$ & 0.1942 & 0.2797 & 0.4201 & 0.2980 & 0.2848 \\
\hline
\end{tabular}

Calculate $(\lambda \max )$ maximum eigenvalue. The $\lambda \max$ is the average of the A4 matrix.

$$
\lambda \max =7.4585
$$

(3) Calculate the consistency using the formula $\mathrm{CI}=[(\lambda \max -\mathrm{n}) / \mathrm{n}-1]$, where $\mathrm{n}$ is the order of the matrix. The consistency index for the present problem is as follows,

$$
\text { Consistency Index }=0.07641
$$

(4) Calculate consistency ratio using the formula $\mathrm{CR}=(\mathrm{CI} / \mathrm{RI})$. The consistency ratio for the present problem is as follows, 


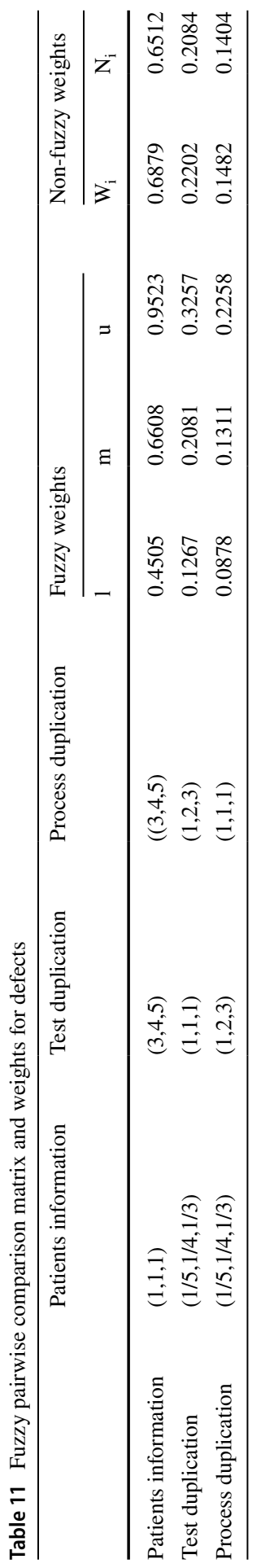


Table 12 Random index (RI) based on matrix size [56]

\begin{tabular}{lllllllllll}
\hline$N$ & 1 & 2 & 3 & 4 & 5 & 6 & 7 & 8 & 9 & 10 \\
\hline$R I$ & 0 & 0 & 0.52 & 0.89 & 1.11 & 1.25 & 1.35 & 1.40 & 1.45 & 1.49 \\
\hline
\end{tabular}

Table 13 Defuzzification of fuzzy AHP matrix

\begin{tabular}{llllllllll}
\hline & C-1 & C-2 & C-3 & C-4 & C-5 & C-6 & C-7 & Geometric mean & Defuzzied weights \\
\hline C-1 & 1 & 3 & 2 & 0.345 & 4 & 3 & 3 & 1.85126 & 0.20836 \\
C-2 & 0.345 & 1 & 0.345 & 0.255 & 2 & 0.555 & 0.345 & 0.52920 & 0.05956 \\
C-3 & 0.555 & 3 & 1 & 0.345 & 3 & 3 & 2 & 1.39614 & 0.15713 \\
C-4 & 3 & 4 & 3 & 1 & 5 & 4 & 3 & 2.99468 & 0.33704 \\
C-5 & 0.255 & 0.555 & 0.345 & 0.2033 & 1 & 0.555 & 0.345 & 0.40857 & 0.04598 \\
C-6 & 0.345 & 2 & 0.345 & 0.255 & 2 & 1 & 0.555 & 0.68022 & 0.07656 \\
C-7 & 0.345 & 3 & 0.555 & 0.345 & 3 & 2 & 1 & 1.02505 & 0.11537 \\
\hline
\end{tabular}

Table 14 Consistency index and consistency ratio for each sub-criterion

\begin{tabular}{lll}
\hline Waste category & Consistency index & Consistency ratio \\
\hline Transportation & 0.05305 & 0.09147 \\
Inventory & 0.04996 & 0.08613 \\
Motion & 0.05336 & 0.09201 \\
Waiting & 0.04996 & 0.08613 \\
Overproduction & 0.05305 & 0.09147 \\
Over-processing & 0.05336 & 0.09201 \\
Defects & 0.04803 & 0.08281 \\
\hline
\end{tabular}

Consistency Ratio $=0.0579$

The consistency index and consistency ratio for the sub-criterion are also calculated, which is also less than 0.10 . This indicates that the subjective judgments made in the study are consistent. The consistency index and consistency ratio for each sub-criterion are shown in (Table 14).

\subsubsection{Development of final priority framework}

The final priority framework for leanness in healthcare by prioritizing various waste present in the healthcare delivery process is developed, as shown in (Fig. 2). 


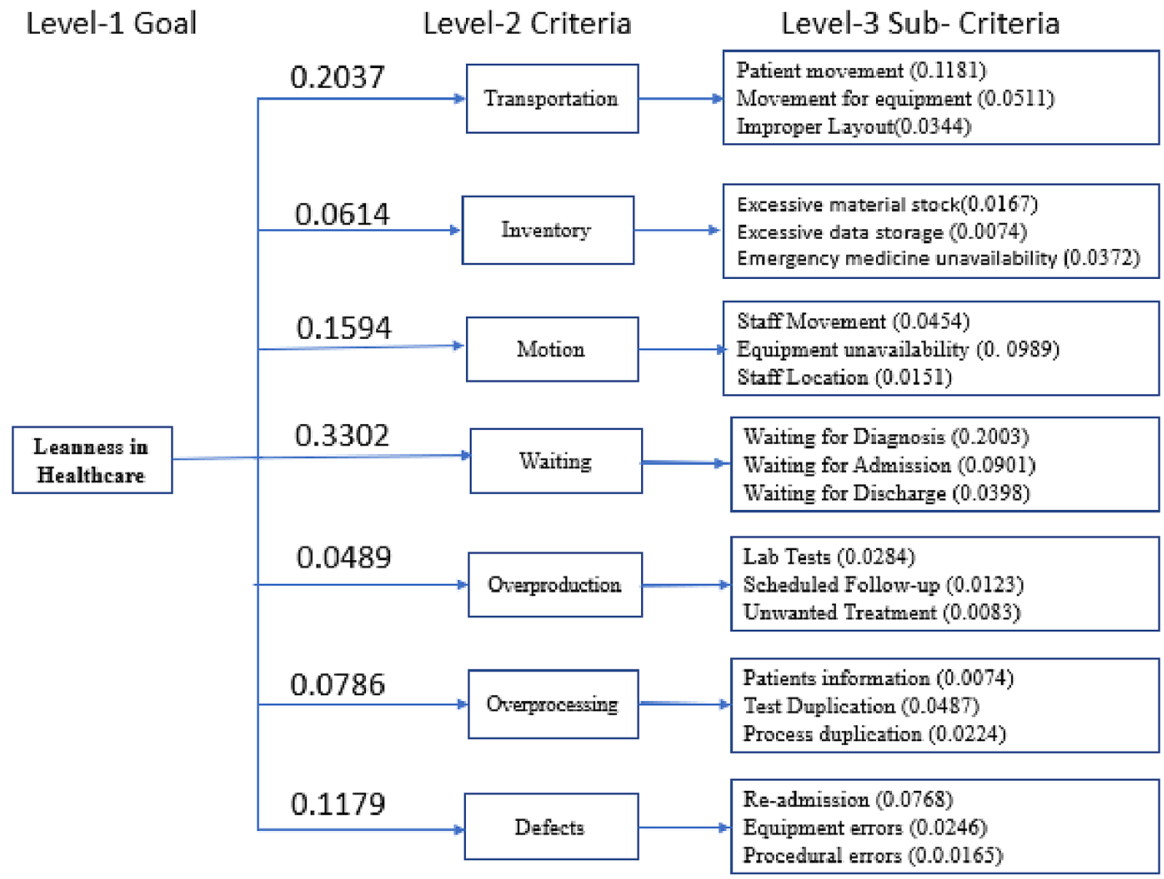

Fig. 2 Leanness priority framework

\section{Results and discussion}

The main focus of lean implementation in healthcare is on waste minimization present in the healthcare delivery process. In the present study, we have identified the seven wastes (criteria) of lean thinking in the healthcare process and the healthcare dimensions (sub-criteria) for each waste. Fuzzy Analytical Hierarchical Process (FAHP) methodology provides the ranking of 7 major healthcare wastes and 21 different healthcare wastes dimensions, which help us to assess the healthcare process's leanness. The output obtained by the fuzzy AHP approach is used to rank various dimensions of healthcare waste, as shown in (Table 15) and (Table 16)

Table 15 Priority of waste for leanness in the healthcare delivery system

\begin{tabular}{lll}
\hline Priority & Waste & Weight \\
\hline 1 & Waiting & 0.3302 \\
2 & Transportation & 0.2037 \\
3 & Motion & 0.1594 \\
4 & Defects & 0.1179 \\
5 & Over-processing & 0.0786 \\
6 & Inventory & 0.0614 \\
7 & Overproduction & 0.0489 \\
\hline
\end{tabular}


Table 16 Priority of sub-criteria for leanness in the healthcare delivery system

\begin{tabular}{|c|c|c|c|}
\hline Rank & Waste dimensions & Weight & Waste category \\
\hline 1 & Waiting for diagnosis & 0.2003 & Waiting \\
\hline 2 & Patient movement & 0.1181 & Transportation \\
\hline 3 & Equipment unavailability & 0.0989 & Motion \\
\hline 4 & Waiting for admission & 0.0901 & Waiting \\
\hline 5 & Re-admission & 0.0768 & Defects \\
\hline 6 & Movement for equipment & 0.0511 & Transportation \\
\hline 7 & Test duplication & 0.0487 & Overprocessing \\
\hline 8 & Staff movement & 0.0454 & Motion \\
\hline 9 & Waiting for discharge & 0.0398 & Waiting \\
\hline 10 & Emergency medicine unavailability & 0.0372 & Inventory \\
\hline 11 & Improper layout & 0.0344 & Transportation \\
\hline 12 & Lab tests & 0.0284 & Overproduction \\
\hline 13 & Equipment errors & 0.0246 & Defects \\
\hline 14 & Process duplication & 0.0224 & Over-processing \\
\hline 15 & Excessive material stock & 0.0167 & Inventory \\
\hline 16 & Procedural errors & 0.0165 & Defects \\
\hline 17 & Staff location & 0.0151 & Motion \\
\hline 18 & Scheduled follow-up & 0.0123 & Overproduction \\
\hline 19 & Unwanted treatment & 0.0083 & Overproduction \\
\hline 20 & Patients information & 0.0075 & Over-processing \\
\hline 21 & Excessive data storage & 0.0074 & Inventory \\
\hline
\end{tabular}

The four significant criteria are waiting, transportation, motion, and defects receiving high importance in the present study. These are mainly related to the operational aspects of the healthcare process. This means that hospitals need to emphasize the highest priority waste, that is, waste due to waiting. Waiting by patients at various stages is a major concern for leanness as it directly impacts patient satisfaction and is most frequently occurring in the hospitals. [1, 67]. Further, waiting for the resources in the healthcare systems plays a vital role as it may reduce service quality and system efficiency [35].

Transportation waste has been given second priority. The unnecessary movement of the patient within the hospital to get treated is disconsolate the patients [37]. Most of the supporting facilities like pathology lab, radiology equipment, pharmacy are located at the designated places resulting in more patient movement. A centralized store location also creates unnecessary waste due to the unavailability of equipment when needed.

The wastes due to motion and defects are given the third and the fourth ranks, respectively. Unnecessary staff movement in search of the equipment or from department to department may, or the procedural errors, delay the patient treatment resulting in reduced system efficiency [37, 48]. Minimization of these types of waste mainly concerns quality practices. Hospitals also need to focus on unnecessary movements of their staff. Additionally, this can also help properly 
utilize the human resource in the hospitals, which is also termed the eighth waste in lean thinking.

The over-processing, inventory and overproduction types of wastes are given the least importance. This shows that these criteria are not so significant in developing patient-centric lean healthcare as these factors do not directly affect the healthcare delivery process's quality. However, some of the dimensions from these factors influence the overall leanness of the healthcare system. For example, the factors like test duplication and unavailability of emergency medicines impact the leanness significantly.

\section{Conclusions}

The healthcare sector has shown exceptional growth in the last three decades, with increasing per capita healthcare expenditure. Recent pandemic has demonstrated that healthcare facilities throughout the world can be overwhelmed by a sudden upsurge in demand for healthcare. Healthcare organizations need to adopt a lean philosophy to seek high quality and cost-effective treatments to achieve operational excellence and competitive advantage.

We have proposed the prioritization of 7 major healthcare wastes and 21 different dimensions of healthcare wastes to assess the healthcare process's leanness. This can be useful to initiate a structured approach for lean healthcare implementation. Our study shows that four of the seven wastes, namely, waiting, transportation, motion, and defects, play a more dominant role in evaluating healthcare systems' leanness. These four wastes contribute almost $80 \%$ to the leanness of the system. Among the seven wastes, waiting is found to be the most prevalent; waiting for a diagnosis is more critical in the healthcare system. The remaining three wastes, over-processing, inventory, and overproduction, receive the least importance in assessing the leanness. This indicates that the healthcare people are more conscious for the healthcare quality. Some of the sub-criteria, like test duplication and emergency medicine unavailability, play an essential role in assessing leanness. These wastes from the overprocessing and inventory category receive high importance in the overall ranking, which is more important from the quality perspective in delivering patient-centric healthcare. The study offers some managerial implications that may assist healthcare professionals in hospitals to initiate measures to improve their healthcare delivery system's leanness. This can help monitor and regulate the lean healthcare implementation process to improve the delivery to patients.

For completeness, we now point out some of the limitations of this study. This study has focused on waste prioritization considering complete hospitals as units. However, the different departments within the hospital may give different results. Further, this study is carried out only in Indian hospitals, located at and near Pune. A comparison of the leanness of Indian hospitals with those in other countries may provide interesting results. The comparison of observed improvements with the prioritization provided by the fuzzy AHP framework presented in this study can be exciting for future research. 
Authors contribution The major work of field study, including data collection and analysis, was carried out by the research student, Mr. Ramkrishna S. Bharsakade. As faculty guides, the overall direction at different stages of research, including data collection and analysis as well as in writing the document, was provided by the faculty guides, Prof. L. Ganapathy and Prof. Padmanava Acharya, and Director, Prof. Manoj K. Tiwari. All authors have read and approved the final manuscript.

Funding All expenses for the research were borne by the research scholar. There was no funding source for the research in the design of the study and collection, analysis, and interpretation of data and in writing the manuscript.

Availability of data and material Data sharing not applicable to this article as no datasets were generated or analyzed during the current study.

\section{Compliance with ethical standards}

Conflict of interest The authors declare that they have no competing interests.

Consent to participate No animals or human tissue or other data used in the study

Consent for publication The author's consent to publish will be provided upon acceptance. Third-party consent is Not Applicable. No images or personal data is reported in the study.

Ethics approval Not Applicable.

Informed consent No animals or human tissue or other data used in the study.

\section{References}

1. Abdallah, A.A.: Healthcare engineering: a Lean management approach. J Healthc. Eng 2020, 1-17 (2020)

2. Adebanjo, D., Laosirihongthong, T., Samaranayake, P.: Prioritizing lean supply chain management initiatives in healthcare service operations: a fuzzy AHP approach. Prod Plan Control 27, 953-966 (2016). https://doi.org/10.1080/09537287.2016.1164909

3. Adebimpe, O.A., Proverbs, D.G., Oladokun, V.O.: A fuzzy-analytic hierarchy process approach for measuring flood resilience at the individual property level. Int J Build Pathol Adapt ahead-ofp:ahead-of-print (2020). https://doi.org/10.1108/IJBPA-10-2019-0094

4. Antony, J., Sunder, M.V., Sreedharan, R., et al.: A systematic review of Lean in healthcare: a global prospective. Int. J. Qual. Reliab. Manag. 36, 1370-1391 (2019). https://doi.org/10.1108/IJQRM $-12-2018-0346$

5. Baril, C., Gascon, V., Cartier, S.: Design and analysis of an outpatient orthopaedic clinic performance with discrete event simulation and design of experiments. Comput. Ind. Eng. 78, 285-298 (2014). https://doi.org/10.1016/j.cie.2014.05.006

6. Bhattacharjee, P., Ray, P.K.: Patient flow modelling and performance analysis of healthcare delivery processes in hospitals: a review and reflections. Comput. Ind. Eng. 78, 299-312 (2014). https://doi. org/10.1016/j.cie.2014.04.016

7. Burgess, N., Radnor, Z.: Evaluating Lean in healthcare. Int. J. Health Care Qual. Assur. 26, 220-235 (2013). https://doi.org/10.1108/09526861311311418

8. Calabrese, A., Costa, R., Levialdi, N., Menichini, T.: Integrating sustainability into strategic decision-making: a fuzzy AHP method for the selection of relevant sustainability issues. Technol Forecast Soc. Change 139, 155-168 (2019). https://doi.org/10.1016/j.techfore.2018.11.005

9. Chan, F.T.S., Kumar, N., Tiwari, M.K., et al.: Global supplier selection: a fuzzy-AHP approach. Int. J. Prod. Res. 46, 3825-3857 (2008). https://doi.org/10.1080/00207540600787200

10. Chatterjee, K., Ahmed, S., Samarjit, H.: Prioritization of project proposals in portfolio management using fuzzy AHP. OPSEARCH 55, 478-501 (2018). https://doi.org/10.1007/s12597-018-0331-3 
11. Chen, Y., Kuo, Y.H., Fan, P., Balasubramanian, H.: Appointment overbooking with different time slot structures. Comput. Ind. Eng. 124, 237-248 (2018). https://doi.org/10.1016/j. cie.2018.07.021

12. Dana, L., Carol, J.: Creating an environment for caring using lean principles of the Virginia Mason production system. J. Nurs. Adm. 37, 287-294 (2007)

13. Daultani, Y., Chaudhuri, A., Kumar, S.: A decade of lean in healthcare: current state and future directions. Glob. Bus Rev. 16, 1082-1099 (2015). https://doi.org/10.1177/0972150915604520

14. de Souza, L.B.: Trends and approaches in lean healthcare. Leadersh. Heal Serv. 22, 121-139 (2009). https://doi.org/10.1108/17511870910953788

15. Dotoli, M., Epicoco, N., Falagario, M., Sciancalepore, F.: A cross-efficiency fuzzy data envelopment analysis technique for performance evaluation of decision making units under uncertainty. Comput. Ind. Eng. 79, 103-114 (2015). https://doi.org/10.1016/j.cie.2014.10.026

16. Dulange, S.R., Pundir, A.K., Ganapathy, L.: Prioritization of factors impacting on performance of power looms using AHP. J. Ind. Eng. Int. 10, 217-227 (2014). https://doi.org/10.1007/s4009 2-014-0080-8

17. Fillingham, D.: Can lean save lives? Leadersh. Heal Serv. 20, 231-241 (2007)

18. G, M.: Lean Hospitals, 2nd edn. Productivity Press, New York (2011)

19. Golan, M.S., Jernegan, L.H., Linkov, I.: Trends and applications of resilience analytics in supply chain modeling: systematic literature review in the context of the COVID - 19 pandemic. Environ. Syst. Decis. 40, 222-243 (2020). https://doi.org/10.1007/s10669-020-09777-w

20. Gopalakrishnan, N., Anand, G.: Is the hospital lean? a mathematical model for assessing the implementation of lean thinking in healthcare institutions. Oper. Res. Heal Care 18, 84-98 (2018)

21. Grout, J.R., Toussaint, J.S.: Mistake-proofing Start', healthcare: why stopping processes may be a good start. Bus. Horiz. 53, 149-156 (2009)

22. Grove, A.L., Meredith, J.O., Macintyre, M., et al.: UK health visiting: challenges faced during lean implementation. Leadersh. Heal Serv. 23, 204-218 (2010). https://doi.org/10.1108/1751187101 1061037

23. Haber, N., Fargnoli, M., Sakao, T.: Integrating QFD for product-service systems with the Kano model and fuzzy AHP. Total Qual. Manag. Bus Excell. 31, 929-954 (2020). https://doi. org/10.1080/14783363.2018.1470897

24. Helmold, M.: Lean Management and Kaizen. Springer, Berlin (2020)

25. Hicks, B.J.: Lean information management: understanding and eliminating waste. Int. J. Inf. Manage. 27, 233-249 (2007)

26. Hussain, M., Malik, M.: Prioritizing lean management practices in public and private hospitals. J Health Organ. Manag. 30, 457-474 (2016)

27. Improta, G., Balato, G., Ricciardi, C., et al.: Lean Six Sigma in healthcare: fast track surgery for patients undergoing prosthetic hip replacement surgery. TQM J 31, 526-540 (2019). https://doi. org/10.1108/TQM-10-2018-0142

28. Ivanov, D.: Predicting the impacts of epidemic outbreaks on global supply chains: a simulationbased analysis on the coronavirus outbreak (COVID-19/SARS-CoV-2) case. Transp. Res. Part E 136, 101922 (2020)

29. James, P., Womac, D.T.J.: Lean Thinking, Banish Waste and Creat Wealth in Your Corporation, First. Free Press, New York (2003)

30. Jimmerson, C., Weber, D., Sobek II, D.K.: Reducing waste and errors: piloting lean principles at intermountain healthcare. J. Qual. Patient Saf. 31, 249-267 (2005)

31. Jimmerson, C., Weber, D., Sobek II, D.K.: Reducing waste and errors: piloting lean principles at intermountain healthcare. Jt. Comm. J. Qual. Patient Saf. 31, 249-257 (2005)

32. Joosten, T., Bongers, I., Janssen, R.: Application of lean thinking to health care: issues and observations. Int. J. Qual. Health Care 21, 341-347 (2009). https://doi.org/10.1093/intqhc/mzp036

33. Kaswan, M.S., Rathi, R., Singh, M.: Just in time elements extraction and prioritization for health care unit using decision making approach. Int J Qual Reliab Manag 36, 1243-1263 (2019). https:// doi.org/10.1108/IJQRM-08-2018-0208

34. Kaur, P., Rakesh, V., Mahanti, N.C.: Selection of vendor using analytical hierarchy process based on fuzzy preference programming. OPSEARCH 2014, 16-34 (2014). https://doi. org/10.1155/2014/987690

35. Kelendar, H., Mohammed, A.M.: Lean and the Ecrs principle: developing a framework to minimise waste in healthcare sectors. Int J Public Heal Clin Sci 7, 98-110 (2020) 
36. Khan, S., Khan, M.I., Haleem, A., Jami, A.R.: Prioritising the risks in Halal food supply chain: an MCDM approach. J Islam Mark ahead-of-p:ahead-of-print (2019). https://doi.org/10.1108/ JIMA-10-2018-0206

37. Khorasani, S.T., Cross, J., Maghazei, O.: Lean supply chain management in healthcare: a systematic review and meta-study. Int. J. Lean Six Sigma 11, 1-34 (2020). https://doi.org/10.1108/IJLSS -07-2018-0069

38. Kumar, P., Bera, S., Dutta, T., Chakraborty, S.: Auxiliary flexibility in healthcare delivery system: an integrative framework and implications. Glob J Flex Syst. Manag. 19, 173-186 (2018). https:// doi.org/10.1007/s40171-018-0183-y

39. Kutlu, A.C., Ekmekçioğlu, M.: Fuzzy failure modes and effects analysis by using fuzzy TOPSISbased fuzzy AHP. Expert Syst. Appl. 39, 61-67 (2012). https://doi.org/10.1016/j.eswa.2011.06.044

40. Kwong, C.K., BaiI, H.: A fuzzy AHP approach to the determination of importance weights of customer requirements in quality function delpyment. J. Intell. Manuf. 13, 367-377 (2002). https://doi. org/10.1023/A

41. Laursen, M., Gertsen, F., Johansen, J.: Applying lean thinking in hospitals - exploring implementation difficulties. In: 3rd International Conference on the Management of Healthcare and Medical Technology. Warwick (2003)

42. Li, S., Wei, C.: A large scale group decision making approach in healthcare service based on subgroup weighting model and hesitant fuzzy linguistic information. Comput. Ind. Eng. 144, 1-11 (2020). https://doi.org/10.1016/j.cie.2020.106444

43. Lin, H.F.: An application of fuzzy AHP for evaluating course website quality. Comput. Educ. 54, 877-888 (2010). https://doi.org/10.1016/j.compedu.2009.09.017

44. Loh, H.S., Yuen, K.F., Wang, X., et al.: Airport selection criteria of low-cost carriers: a fuzzy analytical hierarchy process. J. Air. Transp. Manag. 83, 1-10 (2020). https://doi.org/10.1016/j.jairt raman.2019.101759

45. Mangla, Sachin K., Kumar, P., Barua, M.K.: flexible decision modeling for evaluating the risks in green supply chain using fuzzy AHP and IRP methodologies. Glob J Flex Syst. Manag. 16, 19-35 (2015)

46. McCulloch, P., Kreckler, S., New, S., et al.: Effect of a "Lean" intervention to improve safety processes and outcomes on a surgical emergency unit". BMJ 34, 1043-1047 (2010)

47. Pan, N.F.: Fuzzy AHP approach for selecting the suitable bridge construction method. Autom. Constr. 17, 958-965 (2008). https://doi.org/10.1016/j.autcon.2008.03.005

48. Parkhi, S.S.: Lean management practices in healthcare sector: a literature review. Benchmarking 26, 1275-1289 (2019). https://doi.org/10.1108/BIJ-06-2018-0166

49. Radnor, Z., Boaden, R.: Editorial: lean in public services-panacea or paradox? Public Money Manag 28, 3-7 (2008)

50. Radnor, Z., Holweg, M., Waring, J.: Lean in healthcare: the unfilled promise? Soc. Sci. Med. 74, 364-371 (2012)

51. Ren, P., Xu, Z., Liao, H.: Intuitionistic multiplicative analytic hierarchy process in group decision making. Comput. Ind. Eng. 101, 513-524 (2016). https://doi.org/10.1016/j.cie.2016.09.025

52. Robinson, S., Radnor, Z.J., Burgess, N., Worthington, C.: SimLean: utilising simulation in the implementation of lean in healthcare. Eur. J. Oper. Res. 219, 188-197 (2012)

53. Rostamy, A., Shaverdi, M., Amiri, B., Takanlou, F.: Using fuzzy analytical hierarchy process to evaluate main dimensions of business process reengineering. J. Appl. Oper. Res. 4, 69-77 (2012)

54. Rouyendegh, B.D., Oztekin, A., Ekong, J., Dag, A.: Measuring the efficiency of hospitals: a fullyranking DEA-FAHP approach. Ann. Oper. Res. 278, 361-378 (2019). https://doi.org/10.1007/ s10479-016-2330-1

55. Saaty, T.L.: The Analytic Hierarchy Hrocess. McGraw Hill, New York (1980)

56. Saaty, T.L.: Fundamentals of Decision Making and Priority Theory With the AHP. RWS Publications, Pittsburg (2000)

57. Saha, E., Ray, P.K.: Modelling and analysis of healthcare inventory management systems. Opsearch 56, 1179-1198 (2019). https://doi.org/10.1007/s12597-019-00415-X

58. Sharma, A., Borah, S.B., Moses, A.C.: Responses to COVID-19: the role of governance, healthcare infrastructure, and learning from past pandemics. J. Bus. Res. (2020). https://doi.org/10.1016/j.jbusr es.2020.09.011

59. Shaygan, A., Testik, Ö.M.: A fuzzy AHP-based methodology for project prioritization and selection. Soft. Comput. 23, 1309-1319 (2019). https://doi.org/10.1007/s00500-017-2851-9 
60. Shojaie, A.A., Babaie, S., Sayah, E., Mohammaditabar, D.: Analysis and Prioritization of green health suppliers using fuzzy ELECTRE method with a case study. Glob J Flex Syst Manag 19, 39-52 (2018). https://doi.org/10.1007/s40171-017-0168-2

61. Silverio, L., Trabasso, L.G., Pereira Pessoa, M.V.: A roadmap for a leanness company to emerge as a true lean organization. Concurr. Eng. Res. Appl. 28, 3-19 (2020). https://doi.org/10.1177/10632 93X19888259

62. Silvester, K., Lendon, R., Bevan, H.R.S., Walley, P.: Reducing Waiting Times in the NHS: is Lack of Capacity the Problem? Clin Manag 12, 105-111 (2004)

63. Singh, R.K., Acharya, P.: An AHP model approach to supply chain flexibility: a case study of Indian FMCG firm. Oper Supply Chain Manag. Int. J. 7, 64-69 (2014). https://doi.org/10.31387/oscm0 170109

64. Singh, A., Prasher, A.: Measuring healthcare service quality from patients' perspective: using fuzzy AHP application. Total Qual. Manag. Bus Excell 30, 284-300 (2019). https://doi.org/10.1080/14783 363.2017.1302794

65. Singh, M.K., Kumar, H., Gupta, M.P., Madaan, J.: Analyzing the determinants affecting the industrial competitiveness of electronics manufacturing in India by using TISM and AHP. Glob. J Flex Syst. Manag. 19, 191-207 (2018)

66. Singh, S., Kumar, R., Panchal, R., Tiwari, M.K.: Impact of COVID-19 on logistics systems and disruptions in food supply chain. Int. J. Prod. Res. 0, 1-16 (2020). https://doi.org/10.1080/00207 543.2020.1792000

67. Souza, T.A., Roehe Vaccaro, G.L., Lima, R.M.: Operating room effectiveness: a lean healthcare performance indicator. Int. J. Lean Six Sigma (2020). https://doi.org/10.1108/IJLSS-12-2017-0141

68. Spagnol, G.S., Li, L., Newbold, D.:Lean principles in healthcare : an overview of challenges and improvements. In: IFAC Proceedings Volumes. IFAC, pp 229-234 (2013)

69. Stone, K.B.: Four decades of lean: a systematic literature review. Int. J. Lean Six Sigma 3, 112-131 (2012). https://doi.org/10.1108/20401461211243702

70. VanLeeuwen, K.C., Does, R.J.M.M.: Quality quandaries: lean nursing. Qual.Eng 23, 94-99 (2010). https://doi.org/10.1080/08982112.2010.529486

71. Venkata Rao, R.: Decision Making in the Manufacturing Environment Using Graph Theory and Fuzzy Multiple Attribute Decision Making Methods. Springer, Cardiff (2011)

72. Vinodh, S., Prasanna, M., Hari Prakash, N.: Integrated fuzzy AHP-TOPSIS for selecting the best plastic recycling method: a case study. Appl. Math. Model. 38, $4662-4672$ (2014). https://doi. org/10.1016/j.apm.2014.03.007

73. Virtue, A., Chaussalet, T.: Healthcare planning and its potential role increasing operational efficiency in the health sector. J Enterp Inf Manag 26, 8-20 (2013). https://doi.org/10.1108/17410 391311289523

74. Vishwakarma, V., Garg, C.P., Barua, M.K.: Modelling the barriers of Indian pharmaceutical supply chain using fuzzy AHP Vinayak Vishwakarma*, Chandra Prakash Garg and Mukesh Kumar Barua. Int. J. Oper. Res. 34, 240-268 (2019)

75. Vries, F., Huijsman, R.: Supply chain management in health services: an overview. Supply Chain Manag. Int. J. 16, 159-165 (2011)

76. Wang, Z.J.: An axiomatic property based triangular fuzzy extension of Saaty's consistency. Comput. Ind. Eng. 137, 1-13 (2019). https://doi.org/10.1016/j.cie.2019.106086

77. Womack, J.P., Jones, D.T., Roos, D.: The Machine that Changed the World. Simon and Schuster, New York (1990)

78. Zadeh, L.A.: Fuzzy sets. Inf. Control 8, 338-353 (1965)

Publisher's Note Springer Nature remains neutral with regard to jurisdictional claims in published maps and institutional affiliations. 